\title{
STUDY OF FILLET STRESSES ON CRANKSHAFT AND ITS NATURAL FREQUENCY
}

\author{
Ajazul Haque ${ }^{1}$, Deepak Dubey ${ }^{2}$, J.C.Jain ${ }^{3}$ \\ ${ }^{1}$ Assistant Professor Viva Institute of Technology University Of Mumbai, India. \\ ajazul_741@rediffmail.com \\ ${ }^{2}$ Assistant Professor Viva Institute of Technology University Of Mumbai, India. \\ deepakdubey977@gmail.com \\ ${ }^{3}$ Assistant Professor Viva Institute of Technology University Of Mumbai, India. \\ jcjain2009@gmail.com
}

\begin{abstract}
Present research paper "Study of Fillet Stresses on Crankshaft and Modal Analysis" is a complete Finite Element Analysis of Crankshaft and validate results are theoretical analysed for 4-cylinder, 4-stroke, turbocharged diesel engine with in-line through crankshaft that used the most of automobile companies for the model analysis. In this study the Crankshaft torsional vibrations are analyzed by using the numerical simulation methods and Causes of failures of Crankshaft. For this research Holzer method is used to determine the natural frequency and mode shape of multi-rotor torsional vibration system. Various Pressures at different crank angles are also taken in the account of analysis. .This study is an important effort to develop the scientific and technical understanding for the failure Crankshaft of any Engine under the line of laws of mechanics.
\end{abstract}

Keywords: Modal Analysis, Torsional Vibration, Fillet Stresses, Natural Frequency. $* * *$

\section{INTRODUCTION}

Crankshaft is important parts of any engine that play important role for the definition of limiting value of bearing the dynamic load of engine. The performances of engines are also dependent on radials and transverse components of various forces at different crank angles of crankshaft. This study of crankshaft torsional vibration analysed by the empirical formulae and iterative procedures, under the assumption that a throw of crankshaft has one degree of freedom is only partially true for torsional modes of vibrations. More degrees of freedom are required to get information about other modes of vibration and stress distribution. Since last decade advent of powerful finite element analysis (FEA) packages have proven good tool to accurately analyse it. The complicated geometry of crankshaft and the complex torque applied by cylinders make their analysis difficult. By optimised meshing and accurate simulation of boundary conditions along with ability to apply complex torque, provided by various FEM packages have helped the designer to carry torsional vibration analysis with the investigation of critical stresses. FEM enables to find critical locations and quantitative analysis of the stress distribution and deformed shapes under loads. However detailed modelling and specialised knowledge of FEM theory are indispensable to perform these analyses with high accuracy. They also require complicated meshing strategies. Simulation of actual boundary conditions to equivalent FE boundary conditions has to be done carefully, because a wrongly modelled boundary condition leads to erroneous results.

\section{DESIGEN OF CRANKSAFT OF DISEL ENGIEN}

The design of crankshaft is given in figure -1.1 with the proper leveling of their parameters and the 3-D modal is given in fig-1.2.

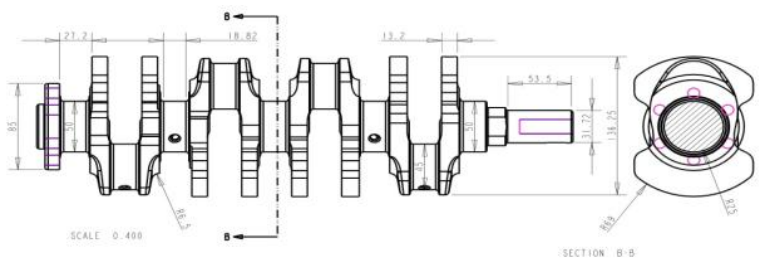

Fig-1.1

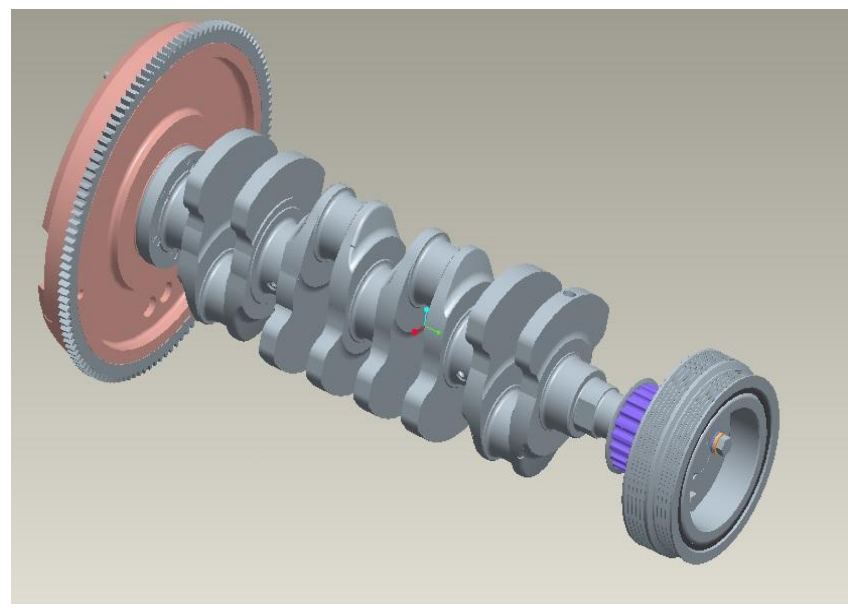

Fig-1.2 


\subsection{ANALYSIS OF CRANSAFT}

Analysis of the designed crankshaft of 4- cylinder 4- stokes turbocharged diesel engine is analyzed the behavior of torsional vibration of this dynamic system. we developed an empirical formula to model the crankshaft as a lumped system consisting of shafts and disk for the calculation of stiffness, inertias and the equivalent length of its. The modeled crankshaft is showed in Fig.1.3 and analyzed lumped parameter approach with the help of Holzer method.

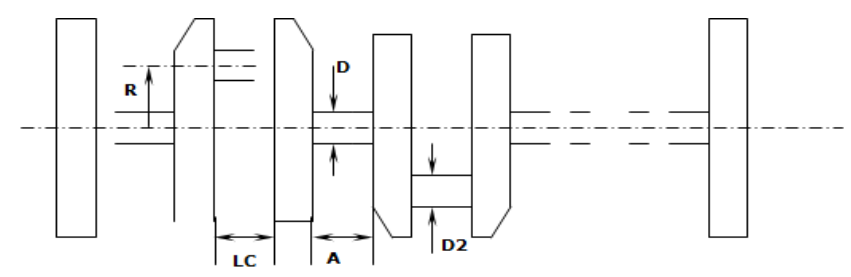

Fig. 1.3.

General Shaft Rotor System [3] Where R is the distance between the Crankshaft axis and Pin centre

- Lc is the length of the Crank Pin

- $\mathrm{D}$ is the Main Journal Diameter

- A is length of the main journal between two adjacent throws

- D2 is the diameter of the crank pin

- Equivalent Length of crankshaft

- $\frac{T}{J}=\frac{G \theta}{L} \quad$ Where, $\mathrm{T}=$ Torque

- $\quad \mathrm{J}=$ Polar Moment of Inertia

$\mathrm{L}=$ Equivalent Length of Crankshaft

$\boldsymbol{\theta}=$ Relative Amplitude

$\mathrm{G}=$ Modulus of Rigidity

$\theta=\theta_{1}+\theta_{2}+\theta_{3}+\theta_{4}+$ $\theta_{n}$

$\frac{T L_{e}}{J_{e} G}=\frac{T L_{1}}{J_{1} G}+\frac{T L_{2}}{J_{2} G}+\frac{T L_{3}}{J_{3} G}+\ldots \ldots \ldots \ldots \ldots \ldots \ldots+\frac{T L_{n}}{J_{n} G}$

Putting all the values we get the equivalent length for a single crank throw.

$L_{e}=D_{e}^{4}\left[\frac{A}{D_{1}^{4}}+\frac{L_{C}}{D_{2}^{4}}+\frac{0.07 L_{c}^{3}}{R^{2} D_{2}^{4}}+\left(\frac{11.58 L_{w} B^{3}}{R D_{1}^{4}}+0.439\right) \frac{R}{L_{w} B^{3}}\right]$

From equation-1.,inertias can be found and finally can be added in the form of a disk having zero stiffness and polar M.I. as given by,

$$
K=\frac{\pi}{32} \frac{D_{e}^{4}}{L_{e}} G
$$

The length of equivalent shaft is given by eqn. 2 . the stiffness can be found out as,

$$
\boldsymbol{J}=\boldsymbol{J}_{s}+\boldsymbol{J}_{p}+\boldsymbol{J}_{w}+\boldsymbol{J}_{r}
$$

\subsection{Final Model Of Crankshaft}

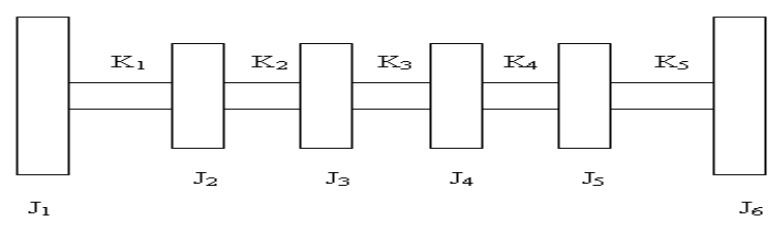

Fig-1.4

For the analysis of crankshaft the final model of crankshaft diagram is given in fig-1.4 is analyzed with the help of the above equivalent system is solved by Holzer iterative method for obtain natural frequencies.

\section{ANALYESIS OF CRANKSHOFT BY HOLZER METHOD}

The general representation of a shaft having many rotors is as shown in Fig.1.4 the rotating shafts can be modeled as a lumped parameters having discs of inertia $\mathbf{J}$ and shafts which are inertia less and having stiffness $\mathrm{K}$ as mention in fig-1.5

\section{GENERAL SHAFT ROTOR SYSTEM}

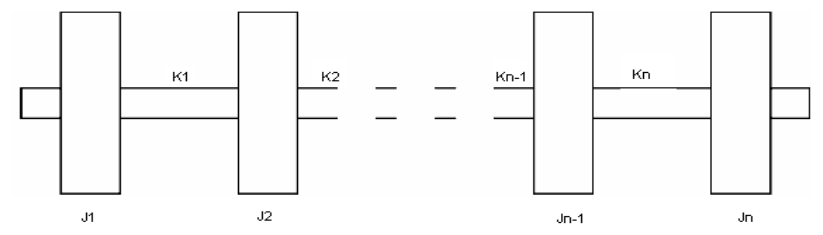

Fig.no.1.5

The equations of motion can be written as, for each rotor;

$$
\begin{aligned}
& \left(K_{1}-J_{1} \omega^{2}\right) \phi_{1}-K_{1} \phi_{2}=\mathrm{O} \\
& -K_{1} \phi_{1}+\left(K_{1}+K_{2}-J_{2} \omega^{2}\right) \phi_{2}-K_{2} \phi_{3}=\mathrm{O} \\
& -K_{2} \phi_{2}+\left(K_{2}+K_{3}-J_{3} \omega^{2}\right) \phi_{3}-K_{3} \phi_{4}=\mathrm{O}(5) \\
& -K_{n-1} \phi_{n-1}+\left(K_{n-1}+K_{n}-J_{n} \omega^{2}\right) \phi_{n}=\mathrm{O}(6)
\end{aligned}
$$

This can be written in matrix form as

$$
\left\{[K]-\omega_{1}^{2}[J]\right\}\{\phi\}=0
$$

Where $[K]$ is the stiffness matrix $[J]$ will be inertia matrix. The equations can be well arranged so as to get branded matrices, which can be solved for [w1] using iterative techniques, transfer matrix methods, finite element methods, etc.

The principle of Holzer method is, when an undamped system is vibrating freely at its natural frequency, no external force or torque is necessary to maintain its vibrations. Recognising this fact Holzer developed a method of calculations of natural frequencies and mode shapes of torsional system by assuming a trial frequency and starting with unit amplitude at one end of the system and progressively calculating the torque and angular displacement to the other end. The frequencies that result into zero external torque or compatible boundary conditions 
at the other end are natural frequencies of the system.

If $\mathrm{n}$ discs are arranged as shown in Fig 1.5, the inertia torques can be written as

$T_{1}=J_{1} \omega^{2} \phi_{1}$

$T_{2}=J_{1} \omega^{2} \phi_{1}+J_{2} \omega^{2} \phi_{2}$

$T_{n}=\sum_{i=1}^{n} J_{i} \omega^{2} \phi_{i}$

Substituting eqn. .6. into eqn.11 to 14 it can be written as

$\phi_{2}=\phi_{1}-\frac{T_{1}}{K_{1}}$

$\phi_{3}=\phi_{2}-\frac{T_{2}}{K_{2}}$

$\phi_{n}=\phi_{n-1}-\frac{T_{n-1}}{K_{n=1}}$

Eqn-9, is first solved by trial and error, with $\varphi 1=1$ for $\omega$ such that $\mathrm{Tn}=0$; this will be natural frequency. Then using eqn. 11 to 12 , the deflections at various rotors can be obtained to plot the mode shapes [3]Fig. 1.5 shows a general variation of residual torque versus trial frequency . The plot cuts frequency axis at natural frequencies.

\section{TORQUE VS TRIAL FREQUENCIES}

This study of analysis of crankshaft is observed that the Natural frequency of Assembly of Crankshaft, Flywheel and Pulley by Holzer's Method are $272.248 \mathrm{~Hz}, 510.984 \mathrm{~Hz}$, $681.209 \mathrm{~Hz}, 1069.93487 \mathrm{~Hz}$ and $1440.4275525 \mathrm{~Hz}$ as shown in fig- 1.6

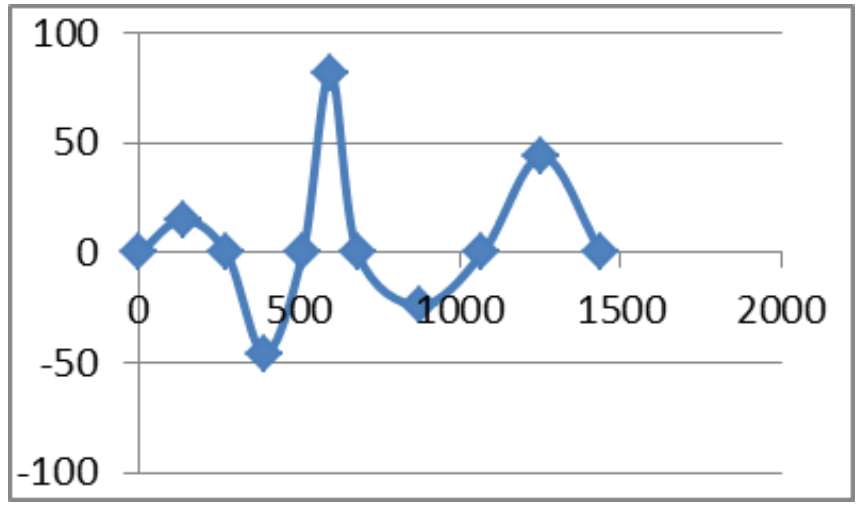

Fig. 1.6

\section{CONCULISION:}

This study of crankshaft is analysed with FEM analysis for crankshaft dynamic analysis. We found the exact critical locations of stresses on crankshaft. Here we observed that the Natural frequency of Assembly of Crankshaft, Flywheel and Pulley by Holzer's Method are $272.248 \mathrm{~Hz}, 510.984 \mathrm{~Hz}$, $681.209 \mathrm{~Hz}, 1069.93487 \mathrm{~Hz}$ and $1440.4275525 \mathrm{~Hz}$. This result reflects location Of the failures in the crankshaft are initiated at the fillet region of the crankpin. Many effects are not corporate in this study.

\section{ACKNOWLEDGEMENT}

We acknowledging to Dr Arun Kumar principal of viva Institute of technology Mumbai University Mumbai, India for constant motivation and support, we also thankful to Professor-M..M. R.. Akhtar Patna science collage Patna university Patna, India for giving unparallel innovative ideas and mathematical sense for this study. We specially thanksfull to late professor laxmikant Varma (Viva institute of technology, Mumbai) for providing technical explation and contents .

\section{REFERENCES:}

[1]. G. K. Groover "Mechanical Vibrations" New Chand \& Bros. 2000

[2]. P. Seshu, "Text book of finite element analysis", Prentice Hall of India, 2008.

[3]. H. Okamura, A. Shinno, T. Yamanaka, "Simple modeling and analysis for crankshaft - Three dimensional vibrations" 1995.

[4]. Xuanyan Lei et. Al., "Simulation on the motion of the crankshaft", 2005.

[5]. S. S. Rao, "Finite Element Method", Fourth edition 2004 Pergamon Press.

[6]. "Hypermesh 6.0 Manual”, 2009

[7]. Singiresu rao, Chapter no. - 5,7, "Mechanical Vibrations"

[8]. Klaus-Jurgen Bathe, "Finite Element Procedures, Prentice -Hall of India Pvt. Ltd, Seventh Indian Reprint, 2003, pages 1-4, 11-12.

[9]. J. N. Reddy , "An Introduction to the Finite Element Method", Tata McGraw Hill, $2^{\text {nd }}$ edition reprint 2003, pages 67-69

[10]. Simon K. Chen and Thomas Chang, "Crankshaft Torsional and Damping simulation ", SAE,1997.

[11]. P. Kreuter, F. Pischinger, "Status of Rules and Methods for assessments of stresses in crankshafts of I.C. Engines", SAE, 2001.

[12]. Edward P. Petkus, Stephan F. Clart, "A simple algorithm for torsional vibrational analysis", SAE, 2003.

[13]. V. Prakash, "The effect of baearing stiffness on crankshaft natural frequency" SAE, 2003. 